\title{
TSpace
}

The University of Toronto's research repository

\section{Accepted Manuscript of Comparative Temporospatial Expression Profiling of Murine Amelotin Protein during Amelogenesis}

\section{How to cite TSpace items}

Always cite the published version, so the author(s) will receive recognition through services that track citation counts, e.g. Scopus. If you need to cite the page number of the TSpace version ${ }^{1}$ because you cannot access the published version ${ }^{2}$, then cite the Tspace version in addition to the published version.

Published version citation:

Somogyi-Ganss E, Nakayama Y, Iwasaki K, Nakano Y, Stolf D, McKee MD, Ganss B. Comparative Temporospatial Expression Profiling of Murine Amelotin Protein during Amelogenesis. Cells Tissues Organs. 2012;195(6):535-49.

TSpace version citation:

Somogyi-Ganss E, Nakayama Y, Iwasaki K, Nakano Y, Stolf D, McKee MD, Ganss B. Comparative Temporospatial Expression Profiling of Murine Amelotin Protein during Amelogenesis. TSpace. Available at http://hdl.handle.net/XXXX/XXXXX. Replace

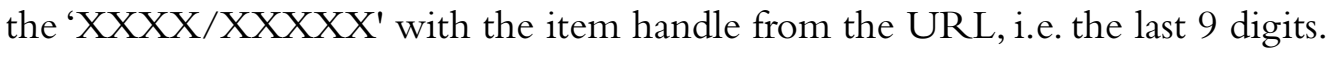

\section{tspace.library.utoronto.ca}

\footnotetext{
${ }_{1}^{1}$ TSpace version: includes the pre-print/original manuscript (version before peer review) and post-print/ accepted manuscript (version after peer-review and editing).

${ }^{2}$ Published version: the publisher's final PDF.
} 


\title{
Comparative Temporospatial Expression Profiling of Murine Amelotin Protein during Amelogenesis
}

\author{
Eszter Somogyi-Ganss ${ }^{a}$ Yohei Nakayama ${ }^{a}$ Kengo Iwasaki ${ }^{d}$ Yukiko Nakano $^{\text {b, c }}$ \\ Daiana Stolf ${ }^{a}$ Marc D. McKee ${ }^{b, c}$ Bernhard Ganss ${ }^{a}$ \\ ${ }^{a}$ Matrix Dynamics Group, University of Toronto Faculty of Dentistry, Toronto, Ont., ${ }^{b}$ Faculty of Dentistry, and \\ 'Department of Anatomy and Cell Biology, McGill University, Montreal, Que., Canada; ${ }^{\mathrm{d}}$ Department of Oral and \\ Maxillofacial Surgery, Tokyo Women's Medical University, Tokyo, Japan
}

\section{Key Words}

Amelotin • Amelogenesis • Protein expression • Enamel

\begin{abstract}
Tooth enamel is formed in a typical biomineralization process under the guidance of specific organic components. Amelotin (AMTN) is a recently identified, secreted protein that is transcribed predominantly during the maturation stage of enamel formation, but its protein expression profile throughout amelogenesis has not been described in detail. The main objective of this study was to define the spatiotemporal expression profile of AMTN during tooth development in comparison with other known enamel proteins. A peptide antibody against AMTN was raised in rabbits, affinity purified and used for immunohistochemical analyses on sagittal and transverse paraffin sections of decalcified mouse hemimandibles. The localization of AMTN was compared to that of known enamel proteins amelogenin, ameloblastin, enamelin, odontogenic ameloblast-associated/amyloid in Pindborg tumors and kallikrein 4 . Three-dimensional images of AMTN localization in molars at selected ages were reconstructed from serial stained sections, and transmission electron microscopy was used for ultrastructural localization of AMTN. AMTN was detected in ameloblasts of molars in a
\end{abstract}

transient fashion, declining at the time of tooth eruption. Prominent expression in maturation stage ameloblasts of the continuously erupting incisor persisted into adulthood. In contrast, amelogenin, ameloblastin and enamelin were predominantly found during the early secretory stage, while odontogenic ameloblast-associated/amyloid in Pindborg tumors and kallikrein 4 expression in maturation stage ameloblasts paralleled that of AMTN. Secreted AMTN was detected at the interface between ameloblasts and the mineralized enamel. Recombinant AMTN protein did not mediate cell attachment in vitro. These results suggest a primary role for AMTN in the late stages of enamel mineralization.

Copyright $\odot 2011$ S. Karger AG, Basel

\section{Introduction}

Tooth enamel is the hardest substance in the vertebrate body; it covers the outer surface of teeth and protects them from wear, particularly from attrition during mastication. In spite of continuously being subjected to enormous mechanical stress and large temperature and $\mathrm{pH}$ fluctuations, this natural bioceramic is designed, if properly formed and cared for, to last a lifetime. However, hereditary and non-hereditary developmental defects, inade-

\section{KARGER}

Fax +4161306 1234

E-Mail karger@karger.ch

www.karger.com
(C) 2011 S. Karger AG, Basel

$1422-6405 / 12 / 1956-0535 \$ 38.00 / 0$

Accessible online at:

www.karger.com/cto
Prof. Bernhard Ganss

Mineralized Tissue Laboratory, Matrix Dynamics Group

University of Toronto, Faculty of Dentistry, FitzGerald Building, Room 234

150 College Street, Toronto, ON M5S 3E2 (Canada)

Tel. +1 416978 8728, E-Mail b.ganss@utoronto.ca 


\begin{tabular}{ll}
\hline Abbreviations used in this paper \\
\hline AMBN & ameloblastin \\
AMEL & amelogenin \\
AMTN & amelotin \\
BSA & bovine serum albumin \\
COLL IV & collagen type 4 \\
3D & 3-dimensional \\
DEJ & dentino-enamel junction \\
ENAM & enamelin \\
FN & fibronectin \\
KLK4 & kallikrein 4 \\
microCT & micro-computed tomography \\
ODAM/APIN & odontogenic ameloblast-associated/amyloid in \\
& Pindborg tumors \\
P2 & postnatal day 2 \\
PBS & phosphate-buffered saline \\
PFA & paraformaldehyde \\
SDS & sodium dodecyl sulfate \\
\hline
\end{tabular}

quate oral hygiene and trauma contribute to enamel destruction. Failure of enamel as a tissue leads to failure of the tooth as an organ, requiring costly interventions. Since ameloblasts - the cells responsible for the formation of enamel - are lost after tooth eruption, a natural repair mechanism does not exist. The detailed molecular mechanisms of enamel development must be understood to design and produce novel, natural biomaterials that may be superior to synthetic restorative materials and to allow the development of regenerative therapies for lost tooth enamel. Enamel is produced via a biomineralization process, where precisely regulated structures of carbonate-substituted hydroxyapatite crystals form under the guidance of specific matrix proteins [for a review, see $\mathrm{Hu}$ et al., 2007]. These proteins are produced by ameloblasts - epitheliumderived cells that undergo a defined life cycle; after an initial proliferative phase, they arrange during the differentiation stage into a single cell layer in apposition to mesenchyme-derived odontoblasts, the latter producing the dentin matrix upon which enamel matrix is deposited. During the secretory stage, ameloblasts become polarized, elongated and develop hallmarks of an active secretory cell. At the maturation stage, ameloblasts reduce in size and diminish their secretory activity [for a review, see Zeichner-David et al., 1995; Thesleff and Aberg, 1997]. There is an overall loss of about $50 \%$ of the cells as they undergo apoptosis either during the transition stage immediately preceding the maturation stage, or during their transformation to create the reduced enamel epithelium, which is believed to subsequently fuse with the oral mu- cosa epithelium to form the initial junctional epithelium of the gingiva [Shimono et al., 2003; Nanci, 2007]

Ameloblasts produce specific enamel matrix proteins depending on their differentiation stage. During the secretory stage, the majority ( $>90 \%)$ of ameloblast proteins secreted are amelogenins (AMEL), which exist as a number of different splice variants. AMEL form supramolecular aggregates known as nanospheres, which are believed to control the thickness and stabilize the growth of the apatitic enamel crystals (within prismatic/rod or interprismatic/interrod enamel) [Paine et al., 2000]. Additionally, less abundant protein constituents of developing enamel, such as ameloblastin (AMBN) and enamelin (ENAM), are also produced by ameloblasts at this stage and they likewise play important yet incompletely defined roles during amelogenesis [Paine and Snead, 2005]. The importance of these matrix proteins for enamel development has been independently and consistently demonstrated in murine gene knock-out animal models. AMEL-deficient mice show hypoplastic, disorganized enamel [Gibson et al., 2001], mice lacking exons 5 and 6 of the Ambn gene display severe enamel hypoplasia and abnormally proliferating ameloblasts [Fukumoto et al., 2004] and junctional epithelium defects [Wazen et al., 2009], and ENAM-deficient mice completely lack enamel [Hu et al., 2008]. The proteinaceous matrix that guides the growth of prismatic enamel is subsequently removed by a limited number of specific proteases, namely matrix metalloproteinase 20 (enamelysin) and kallikrein 4 (KLK4) [Lu et al., 2008]. This process during enamel maturation is equally important for proper enamel development as mice lacking matrix metalloproteinase 20 have structurally defective, hypoplastic enamel [Caterina et al., 2002] and KLK4-deficient mice produce brittle enamel with incompletely developed mineral prisms [Simmer et al., 2009]. Thus, the dynamic interplay of all five proteins is required to produce functional enamel as a highly mineralized meshwork of intertwined hydroxyapatite crystals with outstanding hardness yet some flexural strength, purposefully crafted to deliver and withstand the extreme mechanical forces of mastication. However, the structure of enamel is not homogeneous; the initial layer at the dentino-enamel junction (DEJ), and particularly the final, superficial layer at the enamel surface, is structurally distinct from inner (bulk) enamel. Inner enamel is characterized by the parallel arrangement of long apatite crystals within decussating prisms (layered in alternate directions), while outer enamel appears as a relatively thin region where enamel prisms display a honeycomb pattern in both rodents [Moinichen et al., 1996; 
Risnes et al., 1996] and humans [Kodaka et al., 1991]. Subsequent to this, a very thin layer of prismless final enamel is deposited at the enamel surface within which the enamel crystals generally run perpendicular to the tooth surface. Although this is a highly relevant interface for the formation of oral biofilms on the tooth surface, the molecular mechanisms governing the formation of final surface enamel have not been well explored.

Amelotin (AMTN) has recently been described as a novel component of dental enamel [Iwasaki et al., 2005]. The AMTN genes from mouse and human display a similar exon-intron structure and were expressed from loci on chromosomes 5 and 4, respectively - which have been associated with various forms of amelogenesis imperfecta - in close proximity to ENAM, AMBN and the SIBLING (small, integrin-binding ligand N-linked glycoproteins) gene family. AMTN mRNA expression is limited to maturation stage ameloblasts in developing murine molars and incisors. The conceptually translated protein sequence is unique and shows significant homology only with its human orthologue. The AMTN protein is enriched in proline, leucine, glutamine and threonine (52\% of total) and contains a conserved protein kinase (casein kinase 2) phosphorylation site. The protein was found to be secreted by transfected cells in cell culture. In adult rats and mice, it was subsequently found in the basal lamina-like structure of maturation stage ameloblasts of incisors and unerupted molars, as well as in the internal basal lamina of junctional epithelium in molars [Moffatt et al., 2006]. Although we have reported that AMTN mRNA is transiently expressed between postnatal day 2 (P2) and the time of tooth eruption, a systematic analysis of the AMTN protein expression profile during this developmental window has not been conducted. A recent report [Gao et al., 2010] demonstrated immunolocalization of AMTN in early secretory ameloblasts, contradicting both earlier studies that identified AMTN as a marker only of maturation stage ameloblasts [Iwasaki et al., 2005; Moffatt et al., 2006]. To address this discrepancy and to show the overall developmental expression profile in different stages of amelogenesis, in different teeth and at different mouse ages, we have conducted a comprehensive analysis that specifically also addresses the following unanswered questions: (1) what is the expression profile of murine AMTN in molars and incisors from birth to tooth eruption? (2) Is AMTN localized in the enamel matrix, or only within the basal lamina? (3) How does the expression pattern of AMTN compare to that of other enamel proteins? (4) Does the AMTN expression profile provide clues towards biological function?

Amelotin Expression Profiling

\section{Materials and Methods}

All procedures were performed in accordance with an approved animal use protocol issued by the Division of Comparative Medicine, University of Toronto (protocol No. 20008384).

\section{Antibody Production}

The synthetic peptide mAmtn-1 (H2N-GVTDDDDYEMST$\mathrm{COOH}$ ) was synthesized and separately coupled to keyhole limpet hemocyanine and bovine serum albumin (BSA) at the Advanced Protein Technology Centre (Hospital for Sick Children, Toronto, Ont., Canada). The mAMTN-1-keyhole limpet hemocyanine conjugate was used for the production of polyclonal antisera in two white New Zealand rabbits according to a standard 112-day protocol (Harlan Bioproducts for Science, Indianapolis, Ind., USA). The antisera were affinity purified over a primary cyanogen bromide-activated sepharose 4B column (GE Healthcare Bio-Sciences, Piscataway, N.J., USA) coupled to BSA, a second cyanogen bromide-activated sepharose $4 \mathrm{~B}$ column coupled to BSA-mAmtn-1 and eluted with $50 \mathrm{mM}$ glycine- $\mathrm{HCl} / 0.5 \mathrm{M} \mathrm{NaCl}(\mathrm{pH} 2.3)$.

\section{Western Blotting}

Unerupted first and second mandibular molars were carefully dissected from the alveolar bone socket of 10-day-old mice, keeping the enamel organ intact. Native AMTN protein was extracted from 3 first and 3 second molars in $0.4 \mathrm{ml}$ each in basic buffer ( $50 \mathrm{~mm}$ Tris, $\mathrm{pH} 7.5,300 \mathrm{~mm} \mathrm{NaCl}, 1 \times$ protease inhibitor cocktail; Sigma P8340) with the following additives: buffer 1, 0.5\% NP-40; buffer 2, $100 \mathrm{mM}$ EDTA; buffer3, $4 \mathrm{M}$ urea; buffer 4 , $0.2 \%$ sodium dodecyl sulfate (SDS) and $2 \%(\mathrm{v} / \mathrm{v}) \beta$-mercaptoethanol. Protein extracts $(20 \mu \mathrm{l}$ per lane) were separated by $12 \%$ polyacrylamide gel electrophoresis and transferred to a PVDF membrane (Sigma Aldrich, Oakville, Ont., Canada). Subsequently, membranes were blocked overnight at $4^{\circ} \mathrm{C}$ with gentle shaking in Tris-buffered saline $(50 \mathrm{~mm}$ Tris- $\mathrm{HCl}, 150$ $\mathrm{mM} \mathrm{NaCl}, 0.1 \%$ Tween-20; $\mathrm{pH}$ 7.4) containing 5\% skim milk powder and probed with primary rabbit anti-mAmtn-1 antibodies at a 1:200 dilution in blocking solution for $30 \mathrm{~min}$. The secondary goat antirabbit antibody (Cat. No. 172-1019; Bio-Rad, Hercules, Calif., USA) at a 1:25,000 dilution was applied for $1 \mathrm{~h}$ at room temperature. After 6 washes of 5 min each with Tris-buffered saline-Tween-20 at room temperature, signal was detected with Amersham's enhanced chemiluminescence detection kit (GE Healthcare Bio-Sciences), according to the manufacturer's instructions.

\section{Tissue Processing and Immunohistochemistry}

Mandibles of mice at various postnatal ages were dissected and fixed overnight in $4 \%$ paraformaldehyde (PFA) in phosphatebuffered saline (PBS; $\mathrm{pH} 7.2$ ) at $4^{\circ} \mathrm{C}$ with gentle agitation, then demineralized at $4^{\circ} \mathrm{C}$ in $12.5 \%$ EDTA ( $\mathrm{pH}$ 7.0) for several days with daily change of solution. After washing overnight in PBS, tissues were processed for embedding in paraffin using a 'longembedding cycle' for better tissue infiltration. Tissues were sectioned at a thickness of $5 \mu \mathrm{m}$ and mounted on Superfrost PLUS slides (Fisher Scientific, Nepean, Ont., Canada). Immunohistochemistry experiments were performed using the Dako EnVision+ system according to the manufacturer's instructions using the primary antibodies and dilutions described in table 1 . Tissues were counterstained with methylene blue or methyl green, mounted in Suremount medium and photographed under a light microscope (Nikon E400 model). 
Table 1. Summary of primary antibodies and dilutions used in this study

\begin{tabular}{|c|c|c|c|c|}
\hline Primary antibody to & Source & Antibody name or catalogue number & Epitope & Dilution \\
\hline AMTN & Harlan & mAmtn-1 & GVTDDDDYEMST & $1: 500$ \\
\hline APIN & Dr. A. Nanci (Montreal) & rabbit-anti-rat APIN & full-length recombinant rat APIN protein & $1: 10,000$ \\
\hline AMEL & Abcam & Ab59705 & full-length native bovine AMEL protein & $1: 2,000$ \\
\hline $\mathrm{AMBN}$ & Dr. M. Wendel (Stockholm) & rabbit-anti-mouse amelin & full-length recombinant mouse amelin protein & $1: 10,000$ \\
\hline ENAM & Dr. J. Hu (Ann Arbor) & rabbit-anti-mouse ENAM ms223-236 & FEDYEKPKEKDPPK & $1: 500$ \\
\hline KLK4 & Abcam & Ab71234 & peptide from central region of human KLK4 & $1: 50$ \\
\hline
\end{tabular}

In other samples prepared for paraffin embedding, maxillae were dissected from FVB mice (8 weeks old) and immediately immersed in fixative ( $4 \%$ PFA in $0.06 \mathrm{M}$ sodium cacodylate buffer, $\mathrm{pH}$ 7.4) for 1 day at $4^{\circ} \mathrm{C}$. Maxillae were decalcified in 8\% EDTA ( $\mathrm{pH} 7.3$ ) at $4^{\circ} \mathrm{C}$ for 10 days and then dehydrated through a graded series of ethanol followed by routine embedding in paraffin. The paraffin sections of maxillae were deparaffinized and incubated with $2.5 \mathrm{~mm}$ trypsin in $5 \mathrm{mM}$ Tris-HCl buffer ( $\mathrm{pH}$ 7.3) supplemented with $2.25 \mathrm{mM} \mathrm{CaCl}_{2}$ (Sigma, St. Louis, Mo., USA) for 20 min at $37^{\circ} \mathrm{C}$. Following a blocking treatment with PBS containing $10 \%$ swine and $5 \%$ goat sera, sections were incubated with rabbit anti-mouse AMTN antibody (1:400 dilution, described in the Antibody Production section) overnight at $30^{\circ} \mathrm{C}$. A biotinylated swine anti-rabbit IgG $\mathrm{F}\left(\mathrm{ab}^{\prime}\right)_{2}$ fraction (Dako Cytomation Inc., Carpinteria, Calif., USA) at a 1:500 dilution was used as the secondary antibody and incubated with the section for $1 \mathrm{~h}$ at room temperature. Following incubation with EzLink ${ }^{\circledR}$ Extra Avidinalkaline phosphatase (Sigma) for $30 \mathrm{~min}$, immunoreactivity was visualized using a Vector ${ }^{\circledR}$ Red kit (Vector Laboratories Inc., Burlingame, Calif., USA) resulting in pink/red color for positive staining. Counter-staining was performed with methyl green.

\section{Micro-Computed Tomography Analysis of Mouse Molars}

Eight- and 15-day-old murine first and second molars were fixed in 4\% PFA and embedded in polymethyl-metacrylate resin in Eppendorf tubes. Micro-computed tomography (microCT) scans of each tooth were conducted with a microtomography system (MicroCT40, Scanco Medical, Bassersdorf, Switzerland). All samples were scanned at $70 \mathrm{kVp}$ and $117 \mu \mathrm{A}$. The specimens were scanned in high-resolution mode with an $\mathrm{X}, \mathrm{Y}$ and $\mathrm{Z}$ resolution of $8 \mu \mathrm{m}$, and acquisition files were obtained at 300-500 projections each (per $180^{\circ}$ of rotation), $0^{\circ}$ angle increment, $300 \mathrm{~ms}$ of integration time, and 1 frame averaging. Acquisition was automated for batch mode records (12 samples simultaneously) and an overall scan period of $5 \mathrm{~h}$. The final 3-dimensional (3D) images were composed of 150-250 axially cut slices, each $8 \mu \mathrm{m}$ thick. After scanning and reconstruction, the region of interest comprising the molar was drawn at different depths of the 3D dataset, so that the final drawings could be morphed and used to render a $3 \mathrm{D}$ region of interest.

\section{D Rendition of AMTN-Stained Mouse Molars}

Eight- and 15-day-old mouse first and second molars were fixed in $4 \%$ PFA, decalcified in $12.5 \%$ EDTA and sectioned in series. The obtained slides were stained for AMTN as described in the Tissue Processing and Immunohistochemistry section and counterstained with methyl green. All sections were then photo- graphed at $\times 40$ magnification with a Nikon E400 microscope equipped with a Pixelink EL-630 digital camera. The resulting images (141 for 8-day first molar, 121 for 8-day second molar, 110 for 15-day first molar and 120 for 15-day second molar) were sharpened, manually reduced by $50 \%$ and aligned layer by layer in Adobe Photoshop CS2 using the surrounding structures as guidance for best fit. Afterwards, the morphological features of the teeth were cut out around the ameloblast layer with a black background, and stacks were generated with the StackReg plugin of ImageJ software (www.rsb.info.nih.gov/ij/). The stacks were processed with Imaris 6.0 software (Bitplane AG, Zürich, Switzerland). Separate isosurfaces were generated for the tooth and immunohistochemistry signal, with a $Z$ value of 2 voxels. The tooth isosurface was rendered in the blue channel with thresholds between 190 and 235, and with a Gaussian smoothing value of 2 voxels. The immunohistochemistry signal was rendered in the green channel with threshold values of 95-160 without Gaussian smoothing and combined with the first isosurface.

\section{Colloidal Gold Immunolabeling and Transmission Electron} Microscopy for AMTN Localization

For high-resolution, ultrastructural immunocytochemistry, hemi-mandibles from 16-day-old C57BL/6 mice were fixed overnight by immersion in buffered $4 \%$ PFA and $0.1 \%$ glutaraldehyde in $0.1 \mathrm{M}$ sodium cacodylate buffer, $\mathrm{pH}$ 7.2. After decalcification for 2 weeks in $4 \%$ EDTA ( $\mathrm{pH} 7.2$ ) under constant agitation at $4^{\circ} \mathrm{C}$, samples were dehydrated through graded ethanols and embedded in LR white acrylic resin (London Resin Company, Reading, UK). One-micrometer-thick survey sections were cut off the teeth using a Reichert Ultracut E ultramicrotome. Sections were stained on glass slides with toluidine blue for light microscopy, and selected areas were chosen for thin sectioning $(80-100 \mathrm{~nm})$. Thin sections were placed on Formvar ${ }^{\mathrm{TM}}$ - and carbon-coated nickel grids for colloidal gold immunocytochemistry and transmission electron microscopy. Post-embedding immunogold labeling for AMTN was performed on grid-mounted thin sections as performed previously [McKee and Nanci, 1995] using the anti-mouse AMTN antibody described in the Antibody Production section, followed by protein A-gold (14-nm-diameter gold particles; Dr. G. Posthuma, University of Utrecht, Utrecht, The Netherlands). Briefly, grid-mounted tissue sections were floated for $5 \mathrm{~min}$ on a drop of 0.01 M PBS containing 1\% ovalbumin (Sigma A7641) and then transferred and incubated for $1 \mathrm{~h}$ at room temperature on a drop of rabbit anti-AMTN antibody. After this primary incubation, sections were rinsed with PBS, placed again on PBS-1\% ovalbumin for $5 \mathrm{~min}$, followed by incubation for $30 \mathrm{~min}$ at room temperature with the protein A-gold complex. Tissue sections 
Fig. 1. Western blot analysis of native murine AMTN. Proteins that were extracted with various buffers (lanes 1-4) were separated by SDS-PAGE and probed with a crude (a) and affinity-purified (b) rabbitanti-AMTN antiserum. b Lane 5 shows a peptide competition control using the anti-AMTN peptide, and lane 6 shows a peptide competition control using a non-related peptide. AMTN of approximately 34 $\mathrm{kDa}$ could only be extracted with buffer 4 (containing $0.2 \%$ SDS), while the known calcium-binding basement membrane protein SPARC was extracted with buffer 1 (containing NP-40), buffer 2 (containing EDTA) and buffer 3 (containing urea).

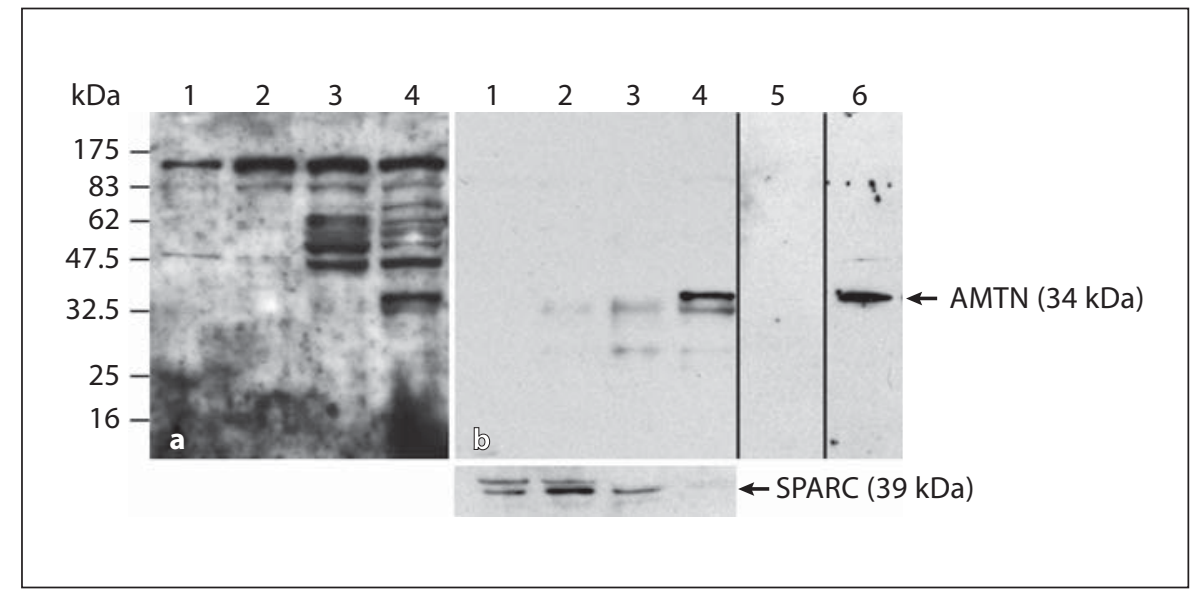

were then washed thoroughly with PBS, rinsed with distilled water, air dried, routinely stained with uranyl acetate and lead citrate and viewed by transmission electron microscopy. Control immunocytochemical incubations consisted of substituting the primary antibody with non-immune rabbit serum or with irrelevant polyclonal antibody, or omitting the primary antibody and using protein A-gold alone. Morphological observations and immunogold labeling patterns were recorded using a JEOL 2000FX-II transmission electron microscope operated at an accelerating voltage of $80 \mathrm{kV}$.

\section{Cell Attachment Assays}

Individual wells of 96-well, non-tissue culture plates (Nunc) were coated overnight at $4{ }^{\circ} \mathrm{C}$ with 5-500 $\mathrm{nM}$ aqueous solutions (100 $\mu$ l per well) of $\mathrm{N}$-terminal His6-tagged recombinant mouse and human AMTN protein, which had been produced in the pET15b expression system (Novagen, Merck KGaA, Darmstadt, Germany) and purified by affinity chromatography on Ni-NTA agarose (Qiagen, Mississauga, Ont., Canada), or with type IV collagen (COLL IV; Sigma C6745) and fibronectin (FN; Sigma F4759) as positive controls, or with BSA (Sigma 85040C) as negative control. Solutions were carefully aspirated and the plates allowed to dry in a cell culture incubator. Adsorption of comparable amounts of all four proteins was confirmed by colloidal gold total protein stain (Cat. No. 170-6527; Biorad, Mississauga, Ont., Canada), according to the manufacturer's instructions. Three different cell types, primary human gingival fibroblasts [Pender and McCulloch, 1991], mouse ameloblast-lineage cells [Nakata et al., 2003] and mouse MC3T3-E1 osteoblasts [Sudo et al., 1983] were grown under the described culture conditions to approximately $80 \%$ confluence in $100-\mathrm{mm}$ tissue culture dishes, washed with PBS, harvested and dispersed into a single-cell suspension by treatment with $0.05 \%$ Trypsin/0.53 mM EDTA (Cat. No. 25300054; Invitrogen, Burlington, Ont., Canada), resuspended in serum-free medium, and 10,000 cells/ $100 \mu \mathrm{l} /$ well were added to the appropriate wells of the coated culture plate. Plates were incubated for $2 \mathrm{~h}$ in a humidified tissue culture incubator at $37^{\circ} \mathrm{C}$ with $5 \% \mathrm{CO}_{2}$. The media was carefully aspirated, wells washed three times with PBS, and attached cells were stained with 4',6diamidino-2-phenylindole dihydrochloride (Cat. No. D1306; Invitrogen) and visualized by fluorescence microscopy.

Amelotin Expression Profiling

\section{Results}

\section{Production of Antisera and Western Blotting}

Murine molar tooth organs were treated with four different reagents for protein extraction and analyzed by Western blotting using the crude rabbit anti-AMTN antiserum (fig. 1a) or an affinity-purified primary antiserum (fig. 1b). Generally, the crude antiserum detected multiple, likely nonspecific bands in the range of about $30-150 \mathrm{kDa}$ in all four extracts (fig. 1a), while the affinity-purified antiserum (fig. 1b) produced one major band of approximately $34 \mathrm{kDa}$ only in the extract containing $0.2 \%$ SDS. Extraction with Tris/ $\mathrm{NaCl}$ buffer containing the non-ionic detergent NP-40, EDTA or urea did not produce any detectable AMTN signal in Western blots. In contrast, SPARC, a well-characterized calcium-binding basement membrane-associated protein, that is also known as BM40 and binds to hydroxyapatite, was extracted with buffers containing NP-40, EDTA or urea, but only little immunoreactive material was found in extracts using SDS-containing buffers. The specificity of the AMTN signal was verified by peptide competition with the peptide used for antiserum production, which abolished any signal (fig. 1b, lane 5). In contrast, competition with an unrelated peptide at the same molar excess did not affect the AMTN signal, but removed several signals at lower molecular weights (fig. 1b, lane 6).

\section{Immunohistochemical Analysis in Pre-Eruptive Molars}

Since our previous mRNA expression analysis had suggested a transient expression for AMTN between P5 and the time of tooth eruption [Iwasaki et al., 2005], we next used the affinity-purified antiserum to analyze the local- 


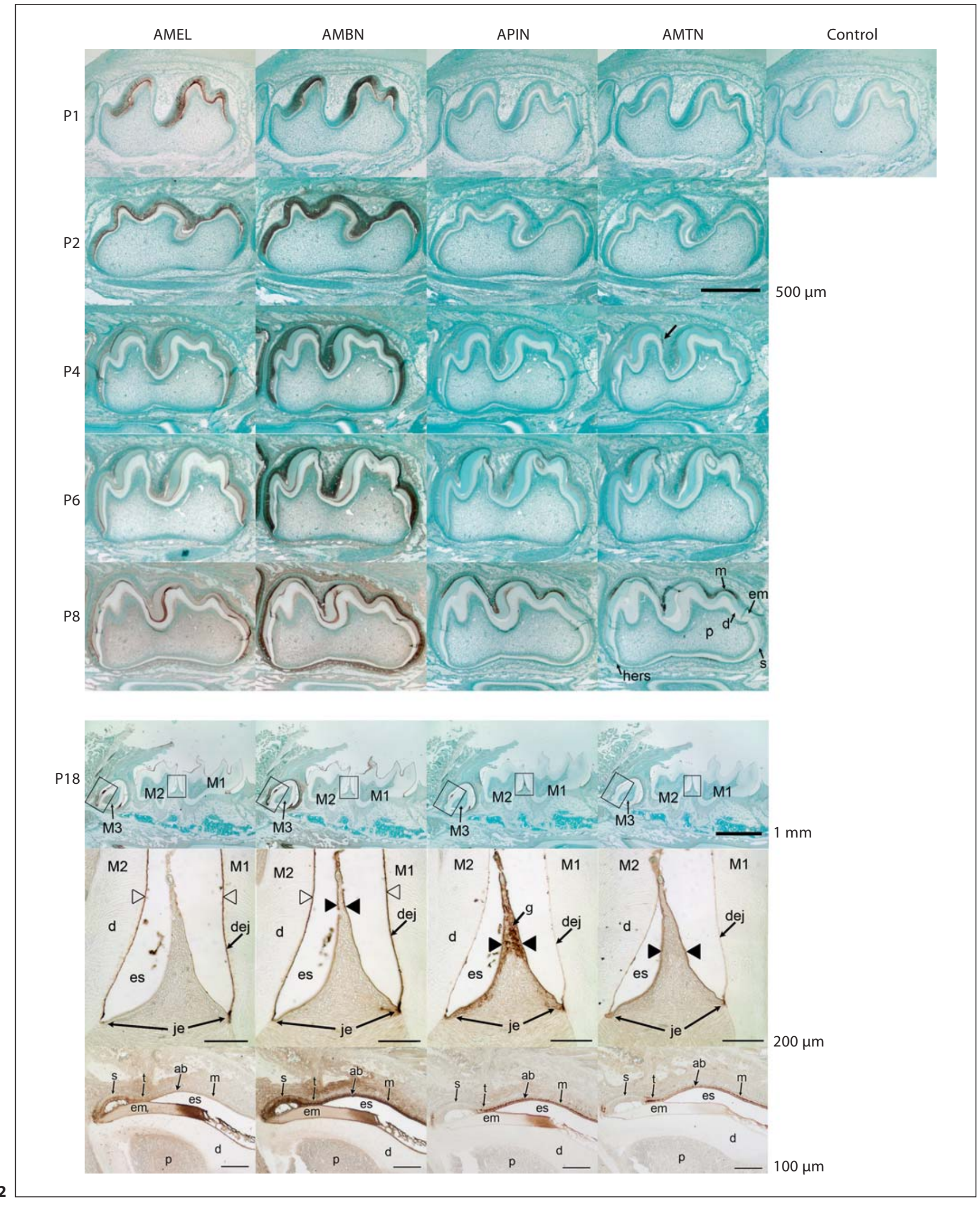


ization pattern of AMTN in molars during pre- and posteruptive stages (fig. 2). In contrast to the two well-characterized enamel proteins AMEL and AMBN, AMTN localization could not be detected in first mandibular molars at P1 and P2; the earliest AMTN signal was found after P4 only in maturation stage coronal ameloblasts (arrow). At P6 and P8, AMTN was clearly localized to ameloblasts, but undetectable in the early enamel matrix or in cells of Hertwig's epithelial rooth sheath, the latter playing an important role in the development of tooth root and periodontal structures. The localization profile of AMTN was highly similar to that of odontogenic ameloblast-associated/amyloid in Pindborg tumors (ODAM/APIN), another recently described enamel protein most highly expressed in maturation stage ameloblasts. Following the eruption of the first mandibular molar at P18, AMTN localization was detected at very low levels in cells of the junctional epithelium; in reduced enamel epithelium cells of the incompletely erupted second molar, AMTN localization was still maintained, and relatively high staining levels were detected in maturation stage ameloblasts of the unerupted third molar. The level of AMTN in the junctional epithelium was relatively low, similar to that of AMBN, while ODAM/APIN staining in the gingiva and junctional epithelium was particularly prominent. The difference in the localization pattern for AMEL and AMBN on the one hand, which were both found in secretory stage ameloblasts of the third molar at this stage, and ODAM/ APIN and AMTN on the other hand, which were found only after the transition from secretory to maturation

Fig. 2. Immunohistochemical staining of AMTN expression in murine molars on P1, P2, P4, P6, P8 and P18 in direct comparison with immunostaining for AMEL, AMBN and ODAM/APIN. The localization of AMTN is only detectable in ameloblasts after P4 (arrow) and occurs in parallel with that of ODAM/APIN, while AMEL and AMBN are both present at all time points. At P18, immunohistochemical staining of the junctional epithelium (je) between the first and second molar (boxed area between M1 and M2) is obvious in the whole gingiva (g) for ODAM/APIN, while AMTN and AMBN are only found in the junctional epithelium directly adjacent to the dento-gingival junction (solid arrowheads). AMEL does not show any expression in the junctional or gingival epithelium. AMEL and AMBN are also found in the DEJ (open arrowheads). At the distal side of the unerupted third molar at P18 (boxed areas at M3), expression of AMEL is predominant in the secretory $(\mathrm{s})$ and transition $(\mathrm{t})$ stage of amelogenesis, AMBN is found during the secretory, transition and maturation (m) stages, but ODAM/APIN and AMTN are found in the transition and maturation stages of amelogenesis. $\mathrm{ab}=$ Ameloblast; $\mathrm{em}=$ enamel matrix; $\mathrm{d}=$ dentin; $\mathrm{p}=$ pulp; $\mathrm{es}=$ enamel space; hers = Hertwig's epithelial root sheath.

Amelotin Expression Profiling stage, is particularly obvious in the unerupted third molar (fig. 2, magnified inserts, P18).

\section{D Reconstruction of AMTN Localization in Molars}

To accurately compare 2D images obtained from complex $3 \mathrm{D}$ objects such as the murine molar, it would be necessary to produce tissue sections at the exact same position and angle in separate samples, especially because significant variations in enamel thickness and structure, including enamel-free areas on non-occlusal surfaces, exist across the coronal surface of mouse molars [Lyngstadaas et al., 1998]. Since this perfect alignment is practically impossible to achieve, we have reconstructed a $3 \mathrm{D}$ localization profile for mouse AMTN in the first and second mandibular molars before (P8) and after (P15) the initiation of tooth root formation (fig. 3). These reconstructions were compared with microCT images of whole molars at the same age as an orientation aid. Although slight deformations and distortions - which are unavoidable during the sectioning process - occasionally produced less-than-ideal 3D structures of whole teeth (apparent as artificially striated patterns), the reconstruction of $3 \mathrm{D}$ images from histological sections generally produced structures that were very similar to those obtained by microCT. Comparing the signal (red) in first and second molars between P8 and P15 in buccal and lingual view, AMTN localization was found mainly around cuspal tips during earlier stages, and more prominently at more apical areas close to the anatomical neck of the tooth. This trend in localization followed the direction of enamel development, which progresses in a coronal-toapical direction. Comparisons of coronal views in first, and more clearly in second, mandibular molars revealed areas of highest AMTN localization at the mesial ridges of lingual and buccal cusps, where enamel formation is most prominent [Lyngstadaas et al., 1998]. Lateral and apical views indicate that AMTN is not expressed to a significant degree in the developing roots.

\section{Immunohistochemical Analysis in Maxillary Incisors}

Sagittal sections of the maxillary incisor at P5 displayed the entire spectrum of ameloblast and enamel development and maturation from secretory to late maturation stages. Here, the localization of AMTN was not detected in secretory stage ameloblasts, but was dramatically increased at the transition from secretory to maturation stage (fig. 4, panels 2 and 3). AMTN immunostaining was then detected throughout the maturation stage in a superficial layer of the enamel matrix, but not in deeper enamel zones (fig. 4, panels 4-7). At the late enamel mat-

Cells Tissues Organs 2012;195:535-549 


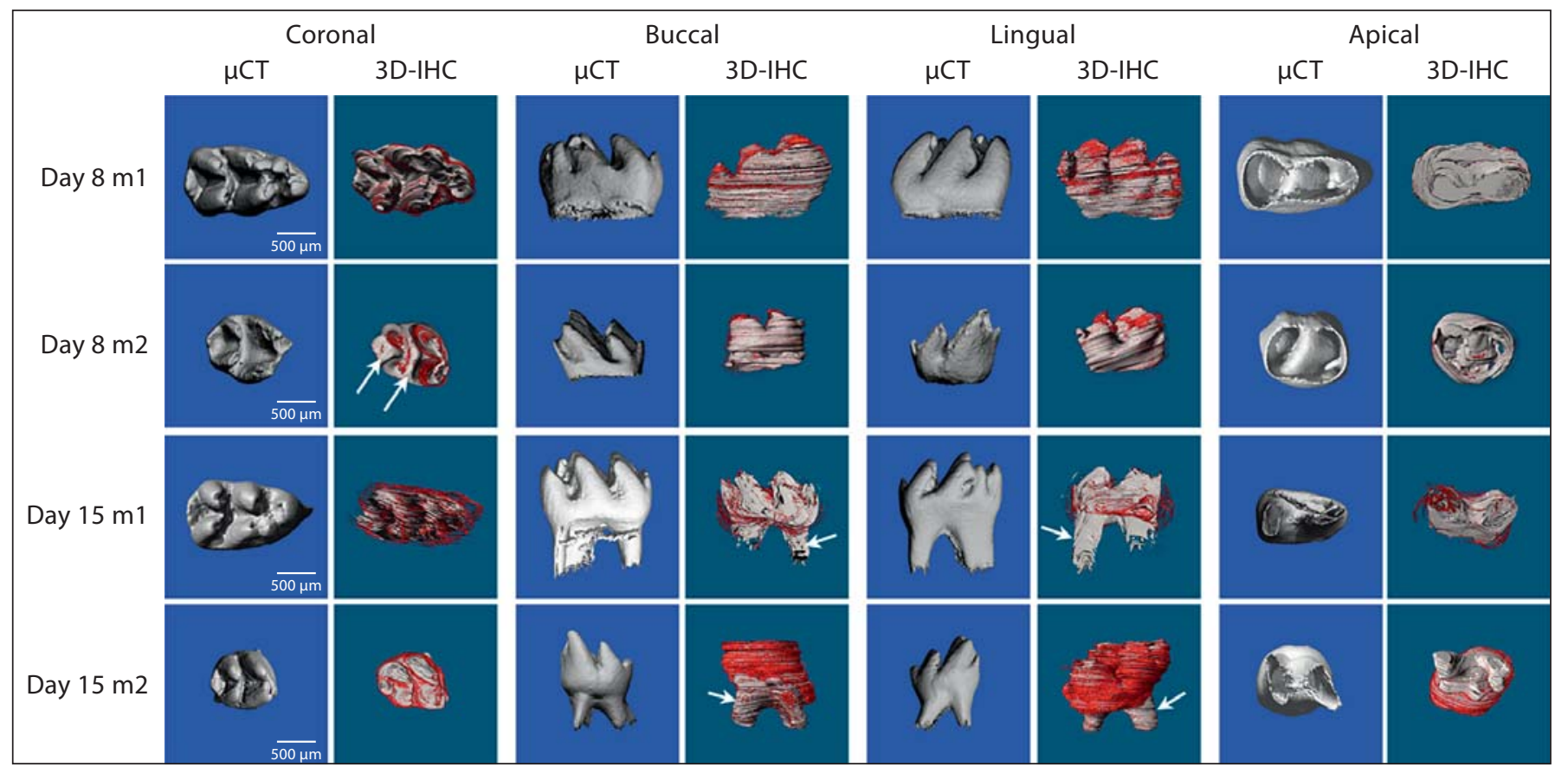

Fig. 3. $3 \mathrm{D}$ immunohistochemistry (3D-IHC) reconstructions of AMTN localization in first (m1) and second (m2) molars at days 8 and 15 viewed from their coronal, buccal, lingual and apical aspects. microCT $(\mu \mathrm{CT})$ images are shown for orientation purposes. The AMTN signal (red) is found only in ameloblasts. Enamel-

uration stage (fig. 4, panel 8), the AMTN signal in the enamel matrix disappeared, but persisted in a narrow, basement membrane-like structure between the apical ameloblast surface and the mineralized enamel throughout subsequent stages toward the reduced enamel epithelium at the incisal end (fig. 4, panels 9-17).

\section{Comparative Localization in Mandibular Incisors \\ (Transverse Sections)}

Since it is again difficult to reproduce the exact angle and position between histological sections of separate samples in the analysis of sagittal incisal sections, we proceeded to analyze the localization of AMTN in transverse sections of the 6-week-old mandibular mouse incisor, and compared this immunostaining with that of AMEL, AMBN and ENAM, as well as with ODAM/APIN and KLK4. A total of approximately 2,000 sections per incisor were prepared from the apical to the incisal end. In this analysis (fig. 5), we confirmed the similar localization profile of AMTN and ODAM/APIN, both of which were not apparent until the transition stage, when they appeared at relative low levels in the bulk, and at much higher levels in the outer, enamel layer (fig. 5, asterisks). The free areas at non-occlusal surfaces of cusps (visible in coronal view of day 8 second molar, arrows) do not show any AMTN immunostaining. Developing root tissues show very low AMTN signals (buccal and lingual views of day 15 first and second molars, arrows). later AMTN localization at the outer and surface enamel that persisted throughout the maturation stage paralleled that of ODAM/APIN, but was clearly distinct from the earlier expression of AMEL, AMBN and ENAM, mainly at the secretory stage. The expression of KLK4 overlapped that of AMTN during the late maturation stage. Notably, there was an additional significant difference in localization profile between AMTN and ODAM/APIN on the one hand, and AMEL, AMBN and ENAM on the other: in transverse sections shown in figure 5 , the first signals for AMTN and ODAM/APIN were observed at the lateral (lingual and buccal) dentino-enamel margins of the developing enamel layer (fig. 5, arrows in sections 300 and 500), while the first signals for AMEL and AMBN appeared clearly in the central portion of the bulk enamel (fig. 5, arrowheads in section 100). ENAM did not show an asymmetric initial localization profile and was evenly found in the entire enamel layer.

\section{Ultrastructural Immunolocalization of AMTN}

To characterize the location of the AMTN protein at the ameloblast-enamel interface in more detail, we conducted immunogold labeling transmission electron mi- 

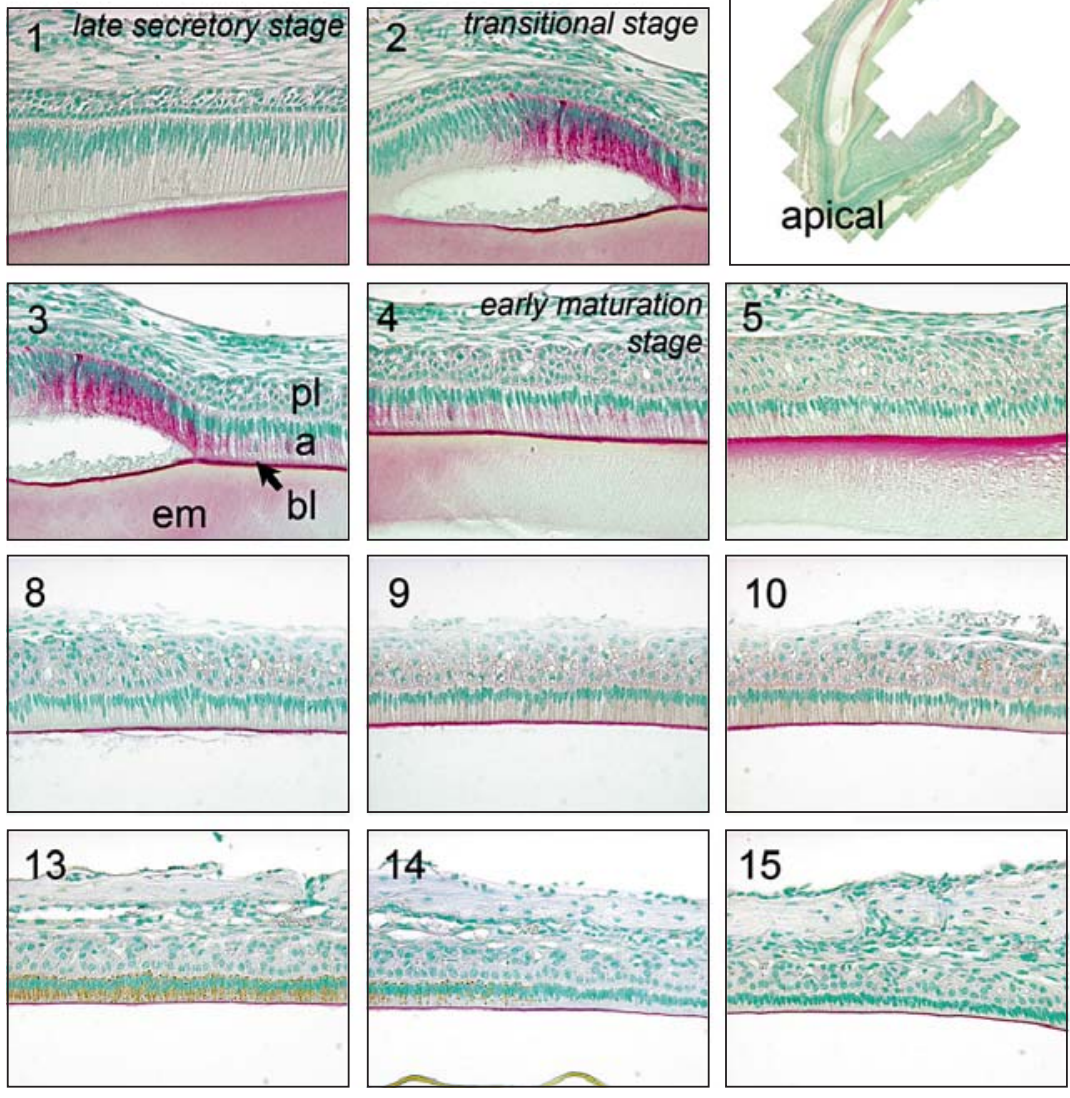
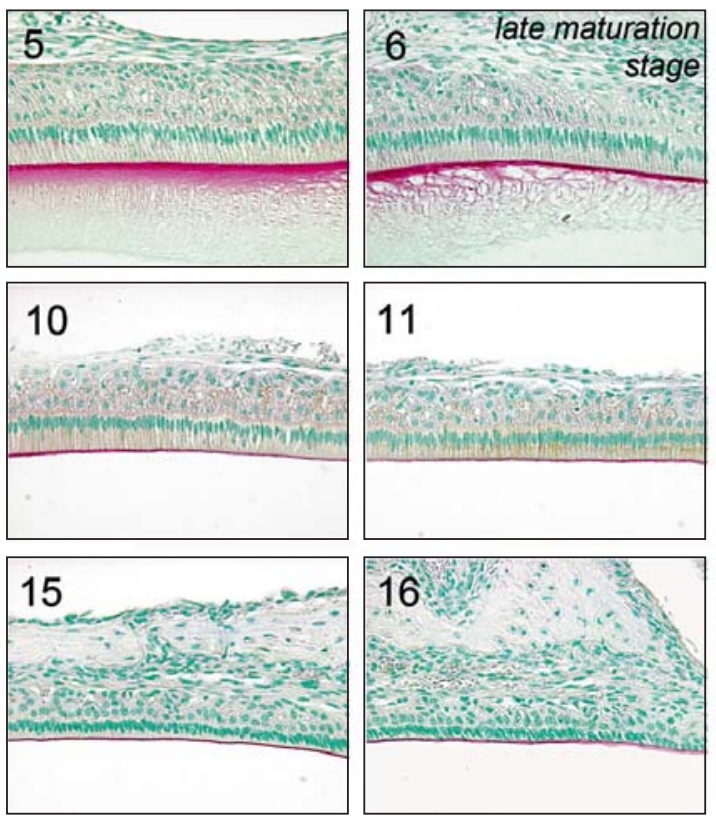

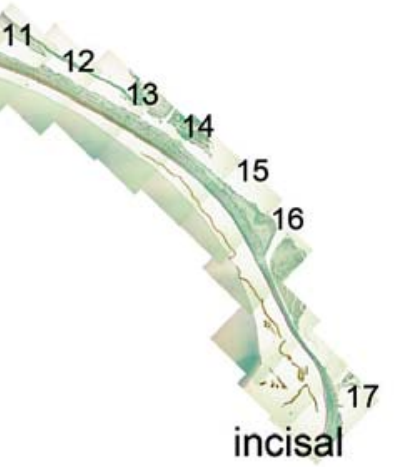

Fig. 4. Localization of AMTN in sagittal sections of maxillary incisors at P5 in apical-incisal direction. The appearance of AMTN (red staining) is first seen by immunohistochemistry at the transitional stage (panel 2), and subsequently, AMTN is localized to the basal lamina-like layer at the ameloblast-enamel interface throughout the enamel maturation stage continuing until the fi- nal stages as the enamel organ transforms into the reduced enamel epithelium (panel 17). Brown staining in panels 11-14 represents naturally occurring iron-ferritin complexes known to result in iron oxide deposition on the labial surface of incisors. em = Enamel matrix; bl = basal lamina-like layer; $\mathrm{a}$ = ameloblasts; $\mathrm{pl}=$ papillary layer of enamel organ. croscopy studies (fig. 6). In the early maturation stage, these analyses revealed the presence of AMTN in ameloblasts in the Golgi apparatus and in secretory vesicles (fig. 6a-c), at very high levels in a layer of variable thickness (on average several hundred nanometers) within the enamel matrix adjacent to the apical surface of early maturation stage ameloblasts, and at lower levels within the deeper outer enamel layer (fig. 6d). At the late maturation stage (fig. 6e), the presence of AMTN was restricted to a narrow layer of approximately $20 \mathrm{~nm}$ directly adjacent to the apical ameloblast surface exactly at the enamel surface. Application of rabbit preimmune serum as a negative control did not produce any labeling (data not shown).

\section{Cell Attachment Assays}

Based on the restricted localization of AMTN at the interface between enamel and ameloblasts, it is conceivable - and has been speculated earlier [Moffatt et al., 2006] - that the protein mediates cell-matrix attachment. To test this possibility, we have performed cell attachment assays using the full-length recombinant murine and hu- 


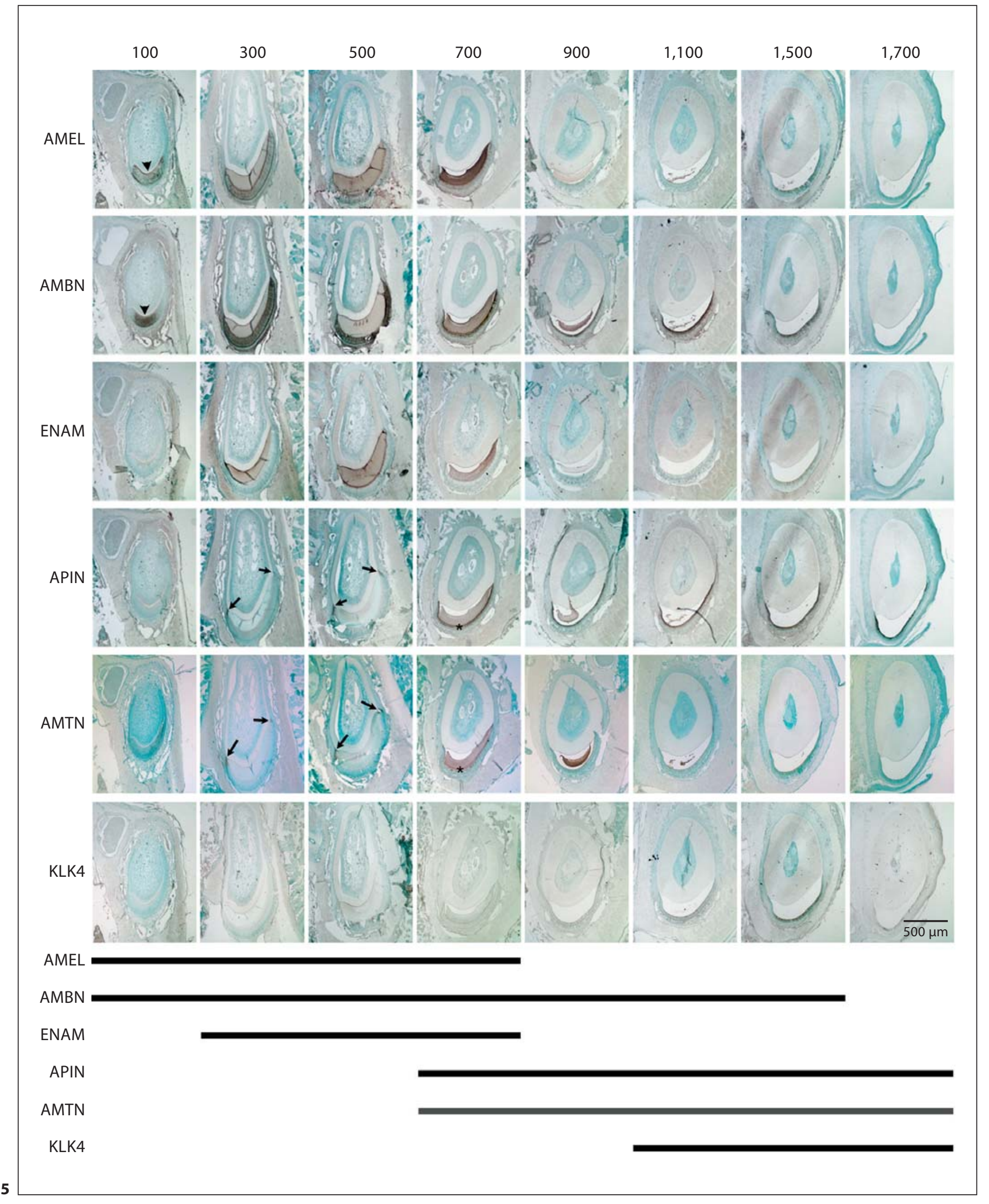


Fig. 6. Immunogold labeling of AMTN in transmission electron micrographs of incisors from decalcified tissue samples. At the early maturation stage (a-d), immunogold labeling (black, round particles) for AMTN in ameloblasts (AM) apposed to enamel (EN) is found in the Golgi region of the cell (b) and in secretory granules (c), here shown near a junctional complex (white arrow) at the apical end of the cells. At the ameloblast-enamel interface, a 200to 500-nm-wide layer of intense immunogold labeling is observed (bracket), with additional mild-to-moderate immunolabeling of the underlying outer enamel matrix. In contrast, AMTN localization later in the maturation stage (e) is found at a very narrow (approximately $20 \mathrm{~nm}$ ) site exactly at the ameloblast-enamel junction at the enamel surface (black arrows). Scale bars $=10 \mu \mathrm{m}(\mathbf{a})$ and $0.5 \mu \mathrm{m}(\mathbf{b}-\mathbf{e})$.
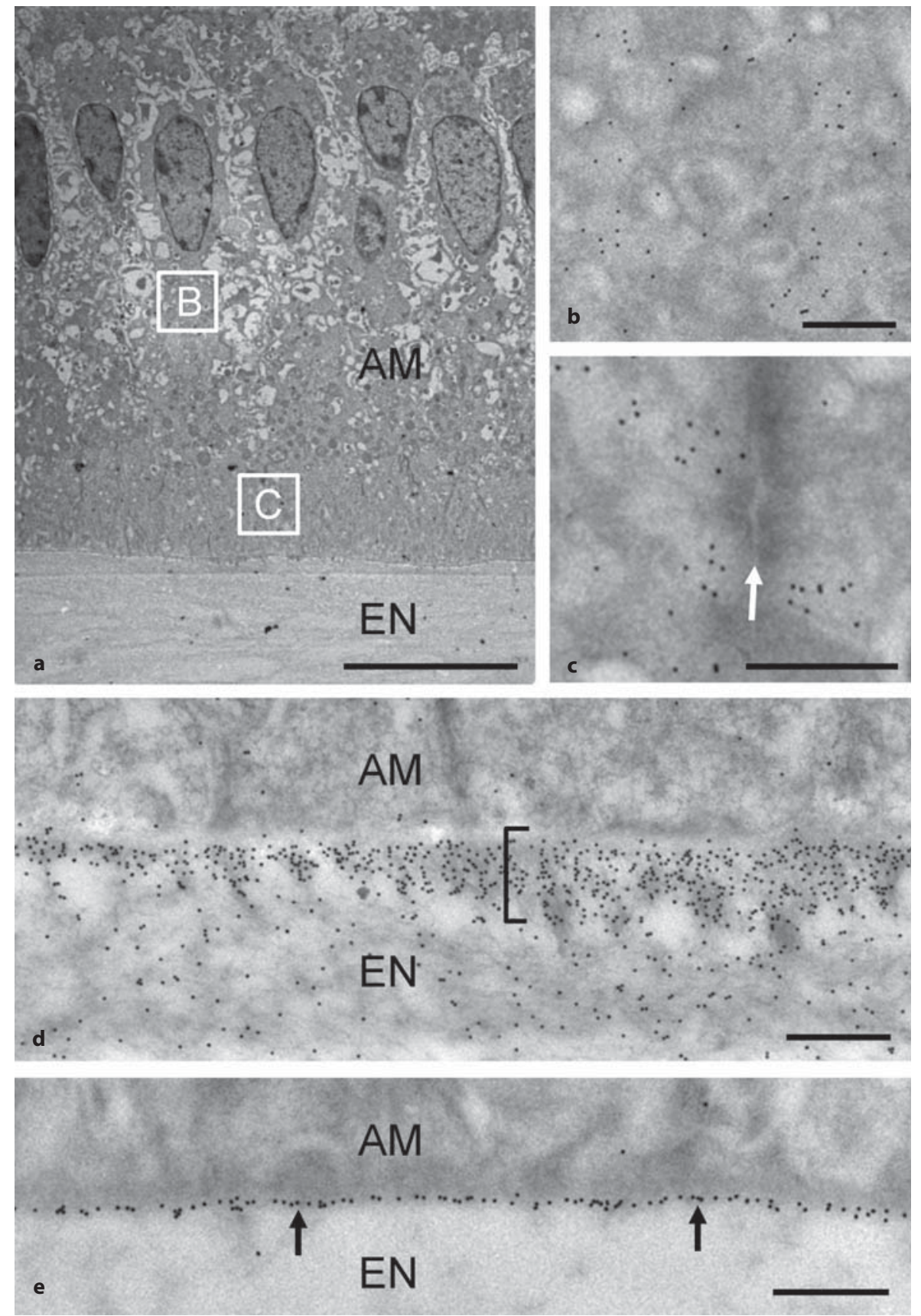

Fig. 5. Localization profiling of AMTN in comparison to other enamel matrix proteins in transverse sections of 6-week-old mandibular incisors. Numbers indicate consecutive numbers of sections from the apical (left) to the incisal (right) end of an incisor. A schematic illustration of localization data (below the micrographs) indicates that AMEL and ENAM are predominantly produced during the secretory and transition stages of amelogenesis. AMBN shows a broader distribution from secretory to maturation stages, but it is absent in the late reduced enamel epithelium (section 1,700, arrowhead). ODAM/APIN and AMTN are produced in parallel from the transition (section 700, asterisks) to the late maturation stage and overlap with the localization of KLK4. Notably, the first appearance of AMEL and AMBN at the secretory stage (section 100, arrowheads) occurs at the center of the curved layer of ameloblasts (labial-most region), while the first signals for AMTN and ODAM/APIN are detected at the lateral (lingual and buccal) margins of the enamel layer (sections 300500, arrows). 


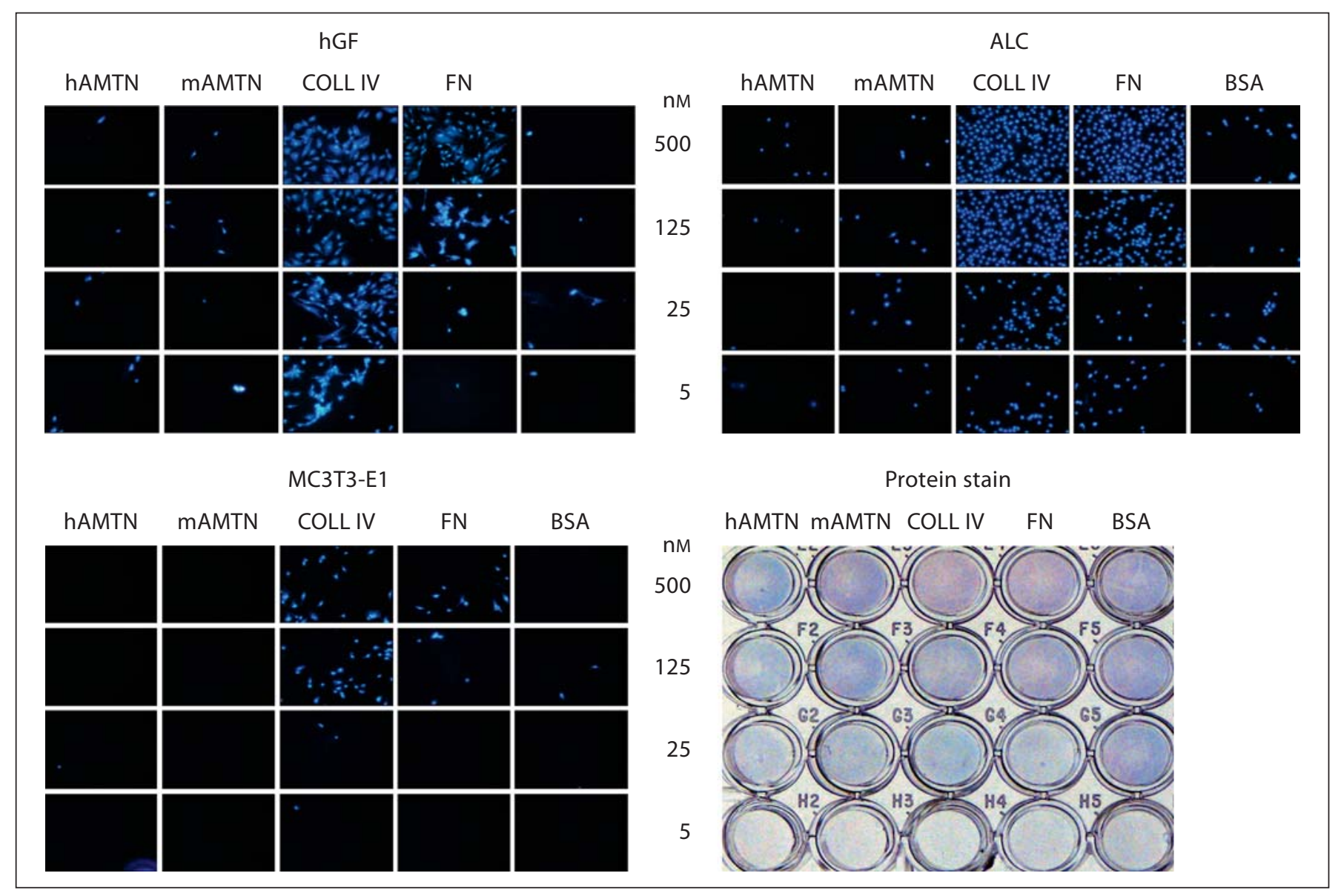

Fig. 7. Cell attachment assays in vitro. Individual wells of multi-well plates were coated with increasing concentrations (5$500 \mathrm{nM}$ ) of recombinant human (hAMTN) and mouse AMTN (mAMTN) as well as of COLL IV and FN as a positive and of BSA as a negative control. After incubation and washing, cells were stained with 4',6-diamidino-2-phenylindole dihydrochloride

man proteins. In these assays (fig. 7), we have used FN and COLL IV as positive and BSA as negative controls. First, we found that similar amounts of all proteins could be adsorbed to polystyrene surfaces within a wide range of concentrations (fig. 7, bottom right panel). As expected, exposure of these coated surfaces to gingival fibroblasts, ameloblast-like cells and osteoblasts resulted in a dose-dependent attachment of all three cell types to FN and COLL IV, but not to BSA. Ameloblast-like cells showed the highest affinity for FN and COLL IV, while the respective affinities of gingival fibroblasts and osteoblasts were slightly, but significantly, reduced. Like BSA, neither murine nor human recombinant AMTN mediated attachment of any cell types over the entire concentration range examined.

(blue). Human gingival fibroblasts (hGF), murine ameloblast-like cells (ALC) and osteoblasts (MC3T3-E1) all attached to COLL IVand $\mathrm{FN}$-coated surfaces in a dose-dependent manner, but did not show any attachment to either mAMTN or hAMTN beyond that observed for control BSA. Comparable adsorption of all proteins was demonstrated by colloidal gold staining (lower right panel).

\section{Discussion}

Since its initial description [Iwasaki et al., 2005], the AMTN gene has been studied by various groups. The current consensus is that AMTN is a unique, secreted protein that is predominantly expressed by ameloblasts in the enamel organ of various species. Although similarities in genomic organization and evolutionary aspects indicate the existence of one common ancestral gene [Sire et al., 2007], AMTN shows very limited sequence homology to the major enamel matrix protein AMEL, or other enamel proteins coded by genes that are located in the same gene cluster as AMTN. Therefore, it can be anticipated that AMTN plays a unique and specific role during the process of enamel formation. 
In silico predictions for AMTN reveal only low-confidence values for post-translational modifications such as several serine/threonine phosphorylation and O-glycosylation sites. In vitro, two different results were obtained regarding the nature and extent of post-translational modifications of AMTN when the protein was expressed in two different mammalian cell lines [Iwasaki et al., 2005; Moffatt et al., 2006], and this is likely attributable to the differences in processing of the protein during the secretion process. We aimed to analyze modifications of native AMTN by extracting protein with various reagents directly from mouse teeth and determining the molecular weight distribution of immunoreactive bands by Western blotting, using a polyclonal, affinity-purified anti-peptide antibody. In this analysis, we found that AMTN could only be extracted with a buffer containing 0.2\% SDS, which is known to disrupt hydrophobic protein-protein interactions, but not with buffers containing NP-40, EDTA or urea. Furthermore, the extraction profile of AMTN was very different from that of a known mineralassociated, calcium-binding basement membrane protein - SPARC [Timpl, 1989]. Based on the observation that the major immunoreactive band appears at a molecular weight approximately $11 \mathrm{kDa}$ larger than predicted from the primary protein sequence, we conclude that native AMTN is indeed post-translationally modified in vivo, although the nature and extent of these modifications remain to be determined. The fact that AMTN accumulates in the basal lamina-like structure between ameloblasts and mineralized enamel indicates that it may - unlike other enamel matrix proteins at this stage - be protected against proteolytic cleavage and removal. This protection could be afforded by binding to the apatitic enamel crystals as reported for mineral-bound histatins in the acquired enamel pellicle [Siqueira et al., 2010], or by the formation of aggregates to limit the accessibility of potential cleavage sites. The existence of such aggregates is supported by the fact that SDS was required for protein extraction.

Our initial description of the Amtn gene and analysis of its mRNA expression profile in mice have shown that the expression is transient between P2 and P5 and the time of tooth eruption [Iwasaki et al., 2005], and that the sequential expression of Amtn from first to third molar parallels the sequential development and eruption of the three molars in each oral quadrant. Although this expression profile clearly indicates a major role for AMTN in tooth development, the protein expression/localization profile during this time has not been analyzed in detail. In this study, we present the first comprehensive description of the developmental protein localization profile for murine AMTN in molars and incisors, and a direct comparison of AMTN localization to that of AMEL, AMBN, ENAM, ODAM/APIN and KLK4. Two previous studies have conducted limited analyses of the mouse AMTN localization profile, one in adult mice [Moffatt et al., 2006] and one at early postnatal stages [Gao et al., 2010]. The two studies arrive at conflicting conclusions: the former describing the specific localization of AMTN protein in the basal lamina-like structure of maturation stage ameloblasts, distinct from other enamel matrix proteins, and the latter reporting the presence of AMTN in the bulk enamel matrix during the early stages of enamel formation, overlapping with the localization of other enamel matrix proteins. These differences are likely attributable to the use of different peptide antibodies against different epitopes, which had [Moffatt et al., 2006] or had not [Gao et al., 2010] been purified by affinity chromatography. In addition, the overlapping expression of Amtn mRNA with that of Amel, Ambn and Enam [Gao et al., 2010] between $\mathrm{P} 1$ and P19 is not at all surprising, since RNA was extracted from whole mandibles which does not allow any spatial resolution of the respective expression profiles. In the present study, we have generated an anti-mouse AMTN peptide antibody in rabbits, purified it by peptide affinity chromatography and demonstrated its specificity by immunoblotting. Our results are largely in agreement with those observed by Moffatt et al. [2006], showing that AMTN is predominantly secreted by maturation stage ameloblasts with a dramatic increase at the transition from secretory to maturation stage. The results also indicate that AMTN protein localization correlates well with that of its mRNA expression [Iwasaki et al., 2005] and that the secreted protein is predominantly found in the extracellular space adjacent to the apical surface of ameloblasts that express the protein. Its localization during enamel maturation parallels that of ODAM/APIN and, while not mutually exclusive, it is distinct from that of the traditional enamel matrix proteins AMEL, AMBN and ENAM. This difference is most obvious in the continuously growing incisors where the entire developmental progression of ameloblasts starting from the cervical loop and continuing to the reduced enamel epithelium can be observed, which indeed makes the rodent incisor an ideal model system to study amelogenesis. In molars, the temporal and spatial localization patterns of AMTN and other enamel matrix proteins were also different, the latter being most prominently secreted by ameloblasts during the secretory stage. Thus, our study establishes AMTN as a late-stage enamel protein that likely fulfills biological roles distinct from those of other enamel matrix proteins. 
We also analyzed the subcellular localization of AMTN protein by high-resolution, immunogold labeling coupled with transmission electron microscopy. Similar to the observation reported by Moffatt et al. [2006], who described a rather diffuse labeling within the apical basal lamina of rat enamel organ ameloblasts, we found highly specific labeling within a narrower layer of approximately $200 \mathrm{~nm}$ immediately adjacent to the apical cell surface at the transition from secretory to maturation stage ameloblasts. Much lower, albeit above background, immunolabeling within several micrometers of the enamel mineral surface layer was also observed at this stage, indicating that AMTN, or immunoreactive fragments, can indeed be found within the outer enamel layer where hydroxyapatite crystals undergo dramatic structural changes. At the mid-maturation stage, we found exclusive AMTN localization in a basal lamina-like layer of approximately $20-50 \mathrm{~nm}$ at the apical ameloblast surface, but not in the enamel. Together, these results raise the possibility that AMTN may be involved in the formation of both the outer and final enamel layer, which are characterized respectively by parallel enamel prisms and an aprismatic surface layer in rodents and humans.

Immunolocalization studies [Moffatt et al., 2006] in post-eruptive molars of rats and mice have shown a weak, but specific AMTN signal at the dento-gingival junction, particularly at the apical surface of junctional epithelium cells. In this study, we were able to confirm this localization and, for the first time, provide a direct comparison with the enamel matrix proteins AMEL, AMBN and ODAM/APIN; this comparison demonstrates a similar localization for AMTN and ODAM/APIN. However, AMTN was found exclusively in the extracellular apical basal lamina-like structure of the junctional epithelium, while ODAM/APIN showed an additional, more broadly distributed signal within the basal cell layer, similar to that of laminin $\gamma 2$ [Kinumatsu et al., 2009]. This localization profile is indeed intriguing in light of a potential role for AMTN in the attachment of junctional epithelium cells to the mineralized tooth surface. However, this potential role in cell attachment likely requires post-translational modifications and/or interactions with other attachment proteins, since recombinant AMTN alone does not appear to mediate cell attachment (fig. 7). It would thus be interesting to investigate any interactions of AMTN with ODAM/APIN and other attachment proteins in this specialized tissue. Our previous work has not shown any detectable mRNA expression levels in the junctional epithelium of posteruptive molars [Iwasaki et al., 2005]. This is likely due to the lower sensitivity of the in situ hybridization protocol. Based on the observation that we did not find AMTN associated with hemi-desmosomes, which are known to be involved in cell to mineral attachment [Shimono et al., 2003], we experimentally queried whether AMTN could be directly involved in cell adhesion. The results from the in vitro cell adhesion experiments presented here do not support a direct role for AMTN in adhesion of a variety of cell types, including ameloblast-like cells. However, the recombinant proteins used in this assay did not contain any post-translational modifications, which may be functionally relevant for cell adhesion, and most likely occur in vivo. AMTN may also participate indirectly in establishing cell-to-mineral adhesion by binding to other proteins such as integrins, laminins (especially the $\gamma 2$ subunit of laminin 5), or other enamel proteins such as AMBN, and/or by forming homoor hetero-multimeric aggregates. Future studies aimed at identifying such AMTN-interacting proteins, together with ultrastructural analyses in AMTN-deficient mice, will allow more definitive conclusions to be made.

The mineral and matrix in mouse incisor enamel can be divided into four distinct layers from the DEJ to the enamel surface: a thin inner, aprismatic layer, followed by inner or bulk enamel characterized by prisms arranged in alternating decussating patterns, an outer enamel layer with thinner, parallel prisms, and finally a thin, dense, aprismatic final surface layer [Warshawsky, 1971; Moinichen et al., 1996]. The mineral habit in both inner and outer enamel layers has long been recognized as being different from that in bulk enamel, but the mechanisms that are responsible for the structural transitions between these layers are not understood. The vast majority of studies on enamel biomineralization have focused on the mechanisms guiding the apatitic crystal formation within the bulk enamel. Although the initial enamel layer is a critical interface for the establishment of the DEJ, it has only recently been characterized in more detail [Beniash et al., 2006]. At the transition from secretory to maturation stage of amelogenesis, the final enamel layer starts to appear as an aprismatic, densely mineralized zone of 3-5 $\mu \mathrm{m}$ when viewed in transverse section in mice [Moinichen et al., 1996] and as gradually merging mineralized nodules covering the Tomes' process pits in labial en face view in rats [Weile et al., 1993]. The final enamel layer is in direct contact with the oral cavity, and thus, is the very mineral surface that the primary enamel pellicle and cariogenic oral biofilms attach to; but in spite of this obvious clinical relevance, the molecular mechanisms that cause the transition from bulk to outer and from outer to surface enamel have not been elucidated. The initiation of this 
prismless surface enamel layer coincides with the onset of AMTN expression, and AMTN protein is found predominantly in this enamel surface layer (fig. 6b). We thus propose that AMTN may be involved in the transition from bulk to outer enamel and the establishment of the final surface enamel layer. Whether AMTN directly regulates enamel mineralization remains to be investigated, and detailed future analyses of relevant structures in AMTNoverexpressing and AMTN-deficient mice will be required to provide insight into mechanistic details.

\section{Acknowledgements}

We would like to thank Dr. Michel Furtado for his expert assistance in acquiring microCT images, Dr. Nawfal Al Hashimi for his help with immunohistochemical procedures, and Ms. Lydia Malynowsky for her help with the electron microscopy and immunogold labeling work. This study was supported by an Operating Grant (MOP-79449) from the Canadian Institutes of Health Research.

\section{References}

Beniash, E., Z. Skobe, J.D. Bartlett (2006) Formation of the dentino-enamel interface in enamelysin (MMP-20)-deficient mouse incisors. Eur J Oral Sci 114(suppl 1): 24-29, discussion 39-41, 379.

Caterina, J.J., Z. Skobe, J. Shi, Y. Ding, J.P. Simmer, H. Birkedal-Hansen, J.D. Bartlett (2002) Enamelysin (matrix metalloproteinase 20)-deficient mice display an amelogenesis imperfecta phenotype. J Biol Chem 277: 49598-49604.

Fukumoto, S., T. Kiba, B. Hall, N. Iehara, T. Nakamura, G. Longenecker, P.H. Krebsbach, A. Nanci, A.B. Kulkarni, Y. Yamada (2004) Ameloblastin is a cell adhesion molecule required for maintaining the differentiation state of ameloblasts. J Cell Biol 167: 973-983.

Gao, Y., W. Wang, Y. Sun, J. Zhang, D. Li, Y. Wei, T. Han (2010) Distribution of amelotin in mouse tooth development. Anat Rec (Hoboken) 293: 135-140.

Gibson, C.W., Z.A. Yuan, B. Hall, G. Longenecker, E. Chen, T. Thyagarajan, T. Sreenath, J.T. Wright, S. Decker, R. Piddington, G. Harrison, A.B. Kulkarni (2001) Amelogenin-deficient mice display an amelogenesis imperfecta phenotype. J Biol Chem 276: 31871-31875.

Hu, J.C., Y.H. Chun, T. Al Hazzazzi, J.P. Simmer (2007) Enamel formation and amelogenesis imperfecta. Cells Tissues Organs 186: 78-85.

Hu, J.C., Y. Hu, C.E. Smith, M.D. McKee, J.T. Wright, Y. Yamakoshi, P. Papagerakis, G.K. Hunter, J.Q. Feng, F. Yamakoshi, J.P. Simmer (2008) Enamel defects and ameloblast-specific expression in Enam knock-out/LacZ knock-in mice. J Biol Chem 283: 10858-10871.

Iwasaki, K., E. Bajenova, E. Somogyi-Ganss, M. Miller, V. Nguyen, H. Nourkeyhani, Y. Gao, M. Wendel, B. Ganss (2005) Amelotin - a novel secreted, ameloblast-specific protein. J Dent Res 84: 1127-1132.

Kinumatsu, T., S. Hashimoto, T. Muramatsu, H. Sasaki, H.S. Jung, S. Yamada, M. Shimono (2009) Involvement of laminin and integrins in adhesion and migration of junctional epithelium cells. J Periodontal Res 44: 13-20.

Kodaka, T., M. Kuroiwa, S. Higashi (1991) Structural and distribution patterns of surface 'prismless' enamel in human permanent teeth. Caries Res 25: 7-20.
Lu, Y., P. Papagerakis, Y. Yamakoshi, J.C. Hu, J.D. Bartlett, J.P. Simmer (2008) Functions of KLK4 and MMP-20 in dental enamel formation. Biol Chem 389: 695-700.

Lyngstadaas, S.P., C.B. Moinichen, S. Risnes (1998) Crown morphology, enamel distribution, and enamel structure in mouse molars. Anat Rec 250: 268-280.

McKee, M.D., A. Nanci (1995) Postembedding colloidal-gold immunocytochemistry of noncollagenous extracellular matrix proteins in mineralized tissues. Microsc Res Tech 31: 44-62.

Moffatt, P., C.E. Smith, R. St-Arnaud, D. Simmons, J.T. Wright, A. Nanci (2006) Cloning of rat amelotin and localization of the protein to the basal lamina of maturation stage ameloblasts and junctional epithelium. Biochem J 399: 37-46.

Moinichen, C.B., S.P. Lyngstadaas, S. Risnes (1996) Morphological characteristics of mouse incisor enamel. J Anat 189: 325-333.

Nakata, A., T. Kameda, H. Nagai, K. Ikegami, Y Duan, K. Terada, T. Sugiyama (2003) Establishment and characterization of a spontaneously immortalized mouse ameloblast-lineage cell line. Biochem Biophys Res Commun 308: 834-839.

Nanci, A. (2007) Ten Cate's Oral Histology: Development, Structure, and Function. St. Louis, Mosby.

Paine, M.L., M.L. Snead (2005) Tooth developmental biology: disruptions to enamel-matrix assembly and its impact on biomineralization. Orthod Craniofac Res 8: 239-251.

Paine, M.L., D.H. Zhu, W. Luo, P. Bringas Jr., M. Goldberg, S.N. White, Y.P. Lei, M. Sarikaya, H.K. Fong, M.L. Snead (2000) Enamel biomineralization defects result from alterations to amelogenin self-assembly. J Struct Biol 132: 191-200.

Pender, N., C.A. McCulloch (1991) Quantitation of actin polymerization in two human fibroblast sub-types responding to mechanical stretching. J Cell Sci 100: 187-193.

Risnes, S., C.B. Moinichen, D. Septier, M. Goldberg (1996) Effects of accelerated eruption on the enamel of the rat lower incisor. Adv Dent Res 10: 261-269.
Shimono, M., T. Ishikawa, Y. Enokiya, T. Muramatsu, K. Matsuzaka, T. Inoue, Y. Abiko, T. Yamaza, M.A. Kido, T. Tanaka, S. Hashimoto (2003) Biological characteristics of the junctional epithelium. J Electron Microsc (Tokyo) 52: 627-639.

Simmer, J.P., Y. Hu, R. Lertlam, Y. Yamakoshi, J.C. Hu (2009) Hypomaturation enamel defects in Klk4 knockout/LacZ knockin mice. J Biol Chem 284: 19110-19121.

Siqueira, W.L., H.C. Margolis, E.J. Helmerhorst, F.M. Mendes, F.G. Oppenheim (2010) Evidence of intact histatins in the in vivo acquired enamel pellicle. J Dent Res 89: 626630.

Sire, J.Y., T. Davit-Beal, S. Delgado, X. Gu (2007) The origin and evolution of enamel mineralization genes. Cells Tissues Organs 186: $25-$ 48.

Sudo, H., H.A. Kodama, Y. Amagai, S. Yamamoto, S. Kasai (1983) In vitro differentiation and calcification in a new clonal osteogenic cell line derived from newborn mouse calvaria. J Cell Biol 96: 191-198.

Thesleff, I., T. Aberg (1997) Tooth morphogenesis and the differentiation of ameloblasts. Ciba Found Symp 205: 3-12, discussion 12 17.

Timpl, R. (1989) Structure and biological activity of basement membrane proteins. Eur J Biochem 180: 487-502.

Warshawsky, H. (1971) A light and electron microscopic study of the nearly mature enamel of rat incisors. Anat Rec 169: 559-583.

Wazen, R.M., P. Moffatt, S.F. Zalzal, Y. Yamada, A. Nanci (2009) A mouse model expressing a truncated form of ameloblastin exhibits dental and junctional epithelium defects. Matrix Biol 28: 292-303.

Weile, V., K. Josephsen, O. Fejerskov (1993) Scanning electron microscopy of final enamel formation in rat mandibular incisors following single injections of 1-hydroxyethylidene-1,1-bisphosphonate. Calcif Tissue Int 52: 318-324.

Zeichner-David, M., T. Diekwisch, A. Fincham, E. Lau, M. MacDougall, J. Moradian-Oldak, J. Simmer, M. Snead, H.C. Slavkin (1995) Control of ameloblast differentiation. Int J Dev Biol 39: 69-92. 